\title{
Quantification of cytotoxic levels of exotoxin A of Pseudomonas aeruginosa cultivated on simple synthetic medium
}

\author{
Ibtesam Ghadban Auda, Afrah Fahad Abdulkareem * \\ Department of biology, College of Science, Mustansiriyah University, Baghdad, Iraq. \\ *Corresponding author's e-mail: \\ aalfahad17@uomustansiriyah.edu.iqstbg@uomustansiriyah.edu.iq.
}

\begin{abstract}
The leading microorganism of chronic otitis media is $P$. aeruginosa and the most powerful exotoxin of $P$. aeruginosais exotoxin Athat responsible for the cytopathic effect on the host tissues. This study aimed to determine the percentage of tox $A$ gene occurrences on chromosome of the otitis media most prevalentcausative agent, $P$. aeruginosa, study the effect of simple salts-based synthetic medium on the production of exotoxin A and evaluate the effect of produced exotoxin A amounts on mice vital organs. The results showed that $P$. aeruginosa is predominant in otitis media as compared with the others. Furthermore, exotoxin A gene is found on all tested $P$. aeruginosa isolates. Therefore, all toxA positive $P$. aeruginosa isolates were subjected to produce exotoxin A by the cultivation of them on simple synthetic media(with trace iron and omitting the glutamate)and quantification of the exotoxin A by ELISA technique. Pseudomonas aeruginosa isolates were varied in exotoxin A production and were ranged from 78 to $1380 \mathrm{pg} / \mathrm{ml}$. Injection ofpure exotoxin A at low doses within the produced values to mice showed histopathological lesions of mice vital organs; these lesions increase with increasing the injected dose.As a conclusion, $P$. aeruginosa is still in the front of otitis media pathogens and toxA gene is predominant on their chromosomes. Even in poor nutrition conditions and the presence of trace amounts of iron, $P$. aeruginosa isolates are still able to grow and produce exotoxin A at amounts can exert its harmful effect on mice vital organs.
\end{abstract}

Keywords: Pseudomonas aeruginosa, toxA gene, exotoxin A, histopathology. DOI : doi.org/10.46617/icbe6005

\section{1-Introduction}

Inflammation of themiddle ear, otitis media, is the frequenttype of ear infection worldwide (1). The most predominated Gram-negative organisms of otitis arePseudomonas sp. followed by Klebsiellasp., Proteus sp., E. coli, andS. Aureus $(2,3)$. Acute upper respiratory tract infections may extend from the nasopharynx to the middle ear causing acute otitis media. Chronic otitis media, the other type of ear infection, usually caused byPseudomonas aeruginosa, and Staphylococcus aureus $(3,4)$.Pseudomonas aeruginosais also caused malignant otitis externa that common in patients with immunosuppression or diabetes (5).

Exotoxin A (ETA), P. aeruginosa product, is extracellulartoxinencodesbythe chromosomaltox $A$ gene. The toxin is an ADP- ribosyl transferase that inhibitseukaryotic cell protein synthesis, cell death will occur as a consequence(6). There are differences inkilling due to steps after the ADPribosylation of EF2. Moreover, exotoxin A increase mitochondrialpermeability, ultimately, leading to the cell death(7). The apoptosisinduces by exotoxin A depend on the dose of exotoxin A received by the cell.Exotoxin A production needs some conditions, iron-limiting growth 
conditions at special media. The toxAgene is regulated at the transcriptional level by the $\operatorname{reg} A B$ operon gene products. The expression of both tox $A$ and regAB is repressed under the ironabundantenvironment(8). The recent work aimed todetermine the percentage of tox $A$ gene occurrences on chromosome of the otitis media most prevalentcausative agent, $P$. aeruginosa, and to study the effect of simple salts-based synthetic medium on the production of exotoxin A.

\section{2-materials and methods}

\subsection{Samples collection and bacterial identification}

Ear swabs were obtained from 50 individuals complaining of symptoms of otitis media. Patient's age ranging from several months to 80 years, 25 females and 25 males. Ear swabs were collected in the period from January to April 2017 from Al-Kadhymia teaching hospital-Baghdad. Ear swabs were inoculated ordinary media. All obtained isolates were identified initially using biochemical tests according to Forbes et al (9).

\subsection{Molecular identification of P. aeruginosa isolates}

Chromosomal DNA of biochemically identified P. aeruginosa isolateswas extracted using commercially available DNA extraction kit (Promega-USA).To confirm the identification of $P$. aeruginosa isolates, PCR technique was performed using 16SrRNA gene ( $r p s L)$ specific primes set. The sequence of 16SrRNA geneforward primer was 5'-GCAACTATCAACCAGCTGGTG3' whilst the reverse is 5'-GCTGTGCTCTTGCAGGTTGTG-3'. The amplification steps comprising 35 cyclesof denaturation at $95^{\circ} \mathrm{C}$ for 30 seconds, annealing at $57^{\circ} \mathrm{C}$ for 10 seconds and extension at $72^{\circ} \mathrm{C}$ for 25 seconds. Oligonucleotide primers of $16 \mathrm{SrRNA}$ gene wereadapted from Lianes et al and Xavieret al $(10,11)$.

\section{3. tox A gene detection}

To ensure that tox $A$ gene is present on the chromosome of $P$. aeruginosa isolates before exotoxin A been produced by synthetic medium, the toxA gene was detected via PCR using specific primers set, forward primer 5'-GTGCGCTACAGCTACACG-3' and the reverse primer,5'CTTGCCTTCCCAGGTATC-3' $(3,12)$. The rpsL andtoxA genes amplification were performed using Go - Taq green master mix kit (Promega-USA). The cycling protocol of toxA gene amplification comprising an initial denaturing step at $94^{\circ} \mathrm{C}$ for 3 minutes, followed by 32 cycles of $94^{\circ} \mathrm{C}$ for 30 seconds, $57^{\circ} \mathrm{C}$ for 45 seconds and $72^{\circ} \mathrm{C}$ for 1 minute ${ }^{3}$. Chromosomal DNA and PCR products were electrophoresed on agarose gel at concentrations of $1 \%$ and $1.5 \%$, respectively(13).

\section{4. synthesis of simple medium}

Simple synthetic culture media were prepared according to Debell (14), with a major modification represented by omitting of amino acidsand one of the salts and replacing the $\mathrm{FeCl} 3$ in the original paper by FeSO4. The following salts: $0.0427 \mathrm{M} \mathrm{NaCl}, 0.0335 \mathrm{M} \mathrm{KCl}, 0.0014 \mathrm{M}$ Na2HPO4, 0.000415 M MgSO4, 0.000025 M MnCl2.4H20, and0.000001M FeSO4 were dissolved in one liter of distilled water; the $\mathrm{pH}$ was adjusted to 7.5then the medium was sterilized by autoclaving. Aliquots of $5 \mathrm{ml}$ of the media were made and inoculated with the test bacteria then incubated with shaking at $37^{\circ} \mathrm{C}$ for 20 hours in a shaker incubator. 


\subsection{Quantification of exotoxin Aproduction}

Produced exotoxin A was quantified by ELISA techniqueusing standard curve methodutilizing commercially available kit (Cusabio-biotic-USA)and according to manufacturer instructions. The optical density was determined of each well, using a microtiter plate reader (BioTek instrument,Inc.USA) set to $450 \mathrm{~nm}$.

\subsection{In vivo histopathological experiment}

Five groups of Bagg Albino laboratory breed (BALB/c) white males mice aged20 weeks each group consisting of 5 mice were obtained from Al-Kadhymiah center of infertility/ Baghdad.Pure exotoxin A (Cusabio biotech - USA) was twofold diluted and injected intraperitoneally into the five groups. Each group receives anexotoxin A dose differ from each other. The first group injected with $100 \mathrm{pg}$ while the second receive $200 \mathrm{pg}$, third and fourth injected with $300 \mathrm{pg}$ and $400 \mathrm{pg}$ respectively. The fifth group injected with normal saline intraperitoneally and considers as a negative control. Seventy-two hours later, the 5 groups were killed and fourvital organs were isolated (heart, lung, spleen, and liver) from each animal, histopathological sections were prepared, stained with hematoxylin and eosin stain and examined at 40X power(15).

\section{Result}

\subsection{Samples collection and bacterial identification}

Ear swabs culture gave 41 bacterial isolates, 23(56.1\%) was belong to P. aeruginosa. The rest percentage belonged other types of bacteria, Staphylococcus aureus $(29.3 \%)$, E. coli $(4.9 \%)$, Proteus spp. (4.9\%), Enterobacter spp. (2.4\%)and Streptococcus pneumoniae(2.4\%)as shown in the table(1).

Table 1: Aerobic bacterial causative agents of otitis media.

\begin{tabular}{ccc}
\hline Bacteria & No. & Percentage (\%) \\
Pseudomonas aeruginosa & 23 & 56.1 \\
Staphylococcusaureus & 12 & 29.3 \\
E. coli & 2 & 4.9 \\
Proteus spp & 2 & 4.9 \\
Enterobacter spp & 1 & 2.4 \\
Streptococcus pneumoniae & 1 & 2.4 \\
Total & 41 & 100
\end{tabular}

\subsection{Molecular identification of P. aeruginosa isolates}

The extracted DNA of $P$. aeruginosa was fairly pure preparation with satisfied concentration (data not shown). Amplification of rpsL gene revealed 201bp amplicon confirming by that $P$. aeruginosa identification (Figure 1). 


\section{3. toxA gene detection}

All of $P$. aeruginosa isolates $23(100 \%)$ possess chromosomal toxAgene when amplified by PCR technique. Figure (2) show agarose gel electrophoretogram of rpsL (201bp) and toxA (417bp) PCR products, respectively. As shown in figure (2), the lanes reveal the band of interest, tox $A$ (417bp).

\subsection{Quantification of exotoxin Aproduction}

All tox $A$ positive $P$. aeruginosa isolates were subjected to produce exotoxin $\mathrm{A}$ by the cultivation of them on simple synthetic media and quantification of the exotoxin A by ELISA technique. Pseudomonas aeruginosa isolates were varied in exotoxin A production and were ranged from 78 to $1380 \mathrm{pg} / \mathrm{ml}$ (figure 3).

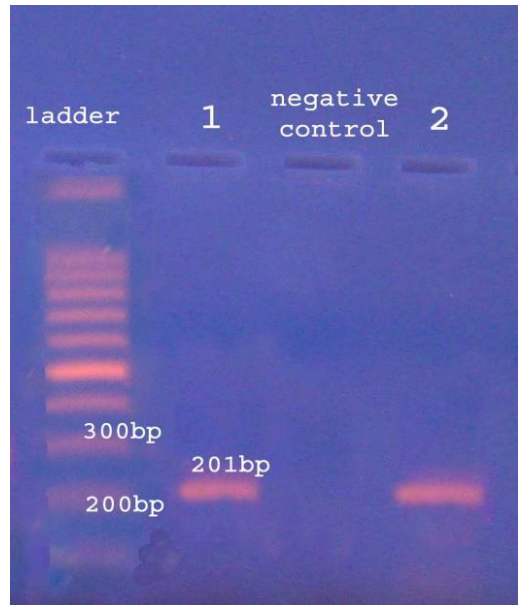

Figure 1: Agarose gel electrophoretogram of $r p s L$ PCR products.

First lane:100bp DNA ladder. Lanes 1and 2: rpsLgene amplicon (201bp) and a lane of negative control in the middle. Electrophoresis was carried out in $1.5 \%$ agarose gel at $(7 \mathrm{~V} / \mathrm{cm})$ for 90 minutes.

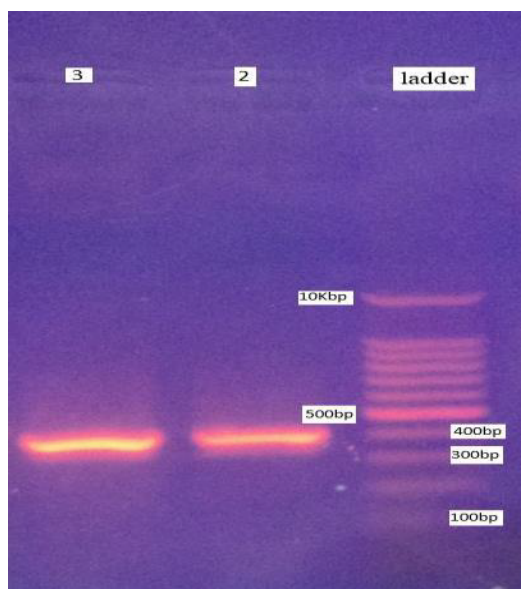

Figure 2: Agarose gel electrophoretogram of toxA PCR products. 
Lane 1:100bp DNA ladder. Lanes 2and 3: toxA gene amplicon (417bp). Electrophoresis was carried out in $1.5 \%$ agarose gel at $(7 \mathrm{~V} / \mathrm{cm})$ for 90 minutes.

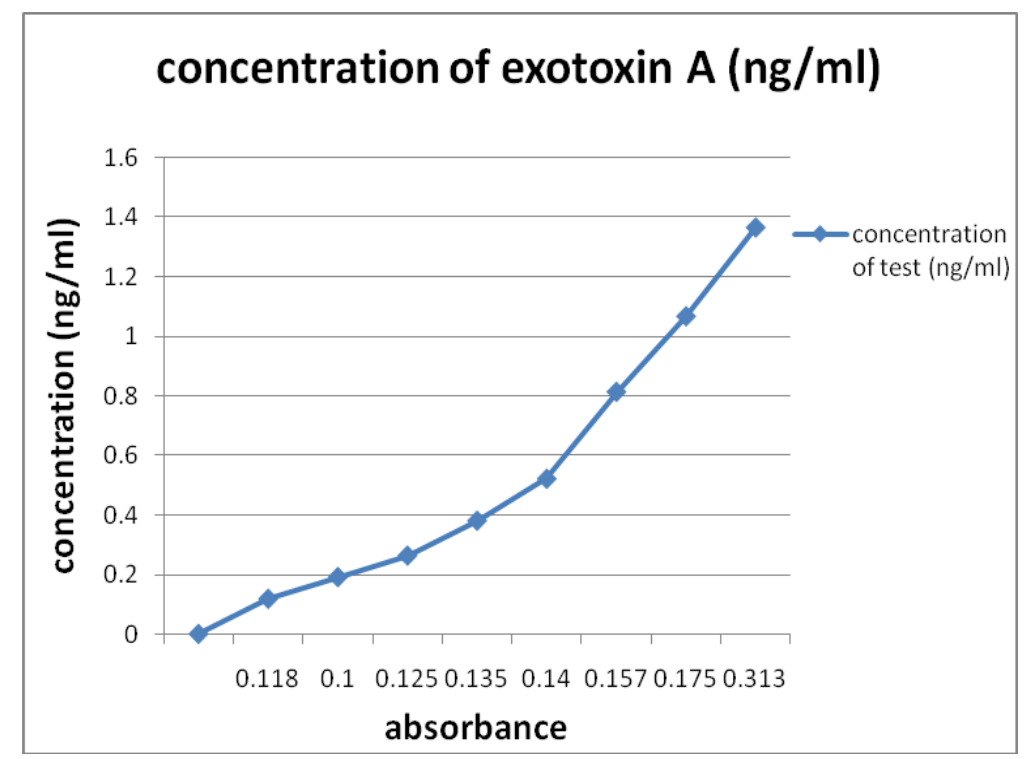

Figure 3: concentration of exotoxin A in the supernatant of Pseudomonas aeruginosa inoculated simple synthetic media.

\subsection{In vivo histopathological study}

The observed lesions of liver tissue include hepatocytes necrosis, blood vessels congestion, infiltration of kuffer cell and ballooning degeneration of hepatocytes. The lesions were severe in the liver of mice group injected with 400pg, especially blood vessels congestion (figure 4). Micelungsreveal some histopathological lesions represented by alveolar walls thickening, infiltration of plasma cells and lymphocytes as well as mucin accumulation in the lumen of alveoli, blood vessels congestion. The severity of these lesionsis increased with the increaseof the injectedamount of the exotoxin A especially blood vessels congestion and alveolar walls thickening (figure 5).

Regarding spleen lesions, degeneration of splenocytes, white pulp enlargement, infiltration of phagocytes cell, and congestion and hyperplasia of blood vessels were observed. The spleen of mice injected with 300 and $400 \mathrm{pg}$ reveal obvious enlargement of white pulp(figure 6). Heart histopathological lesions include congestion of blood vessels especially of the hearts of mice injected with 400pg, cardiac cells necrosis and degeneration and inflammatory cells infiltration (figure 7). 

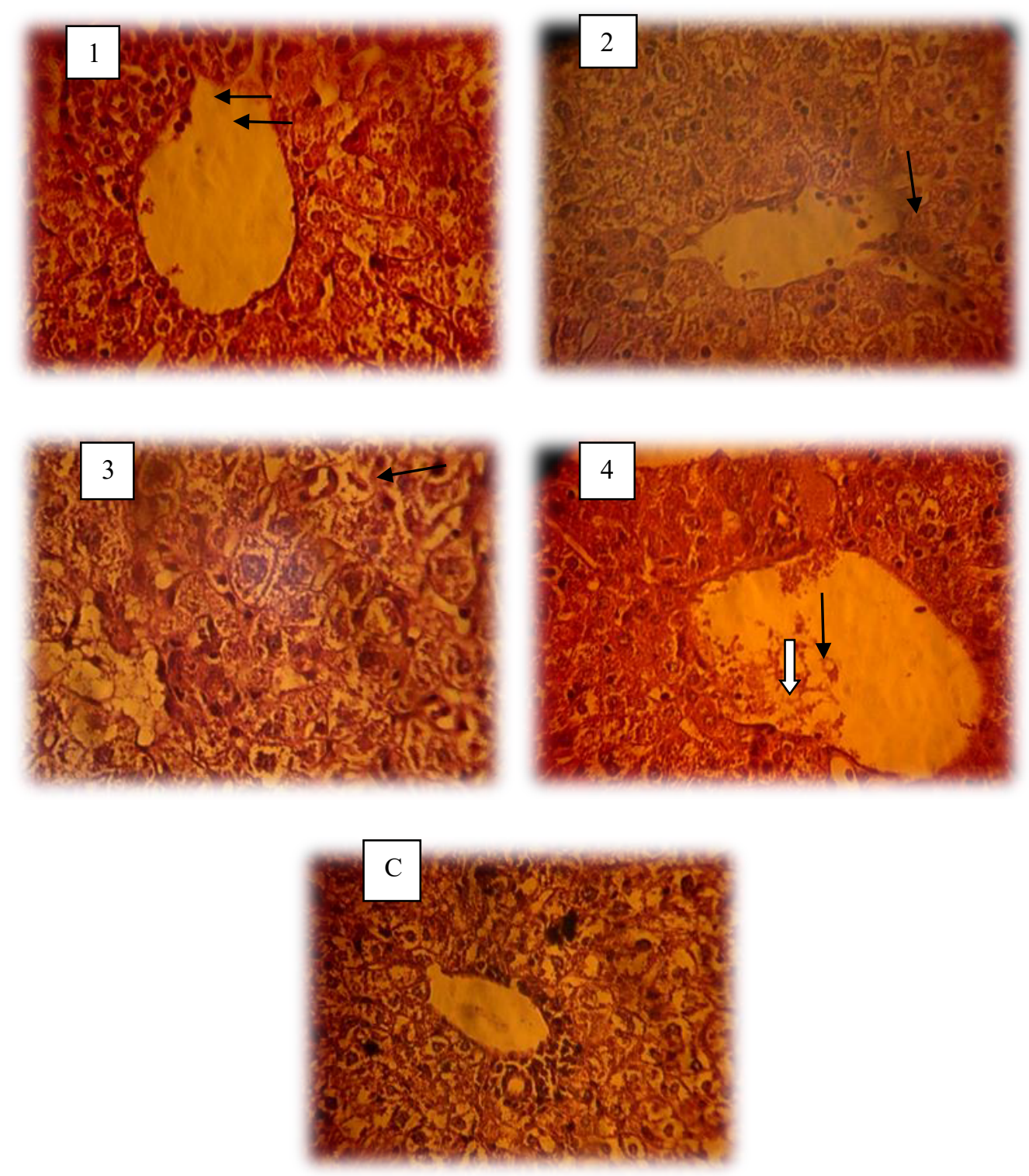

Figure 4: Histopathological sections of mice liver

Sections 1, 2, 3 and 4 liver histopathological sections of mice injected with 100, 200,300 and $400 \mathrm{pg}$ respectively. $\mathrm{C}$ is controlnegative liver.Blood vessels congestion of section 4 (thin black arrow), degeneration and necrosis of hepatocytes is in section 3 (thin black arrow), kuffer cell infiltration is in sections 1, 2 (thin black arrow) and 4 (thick white arrow). 

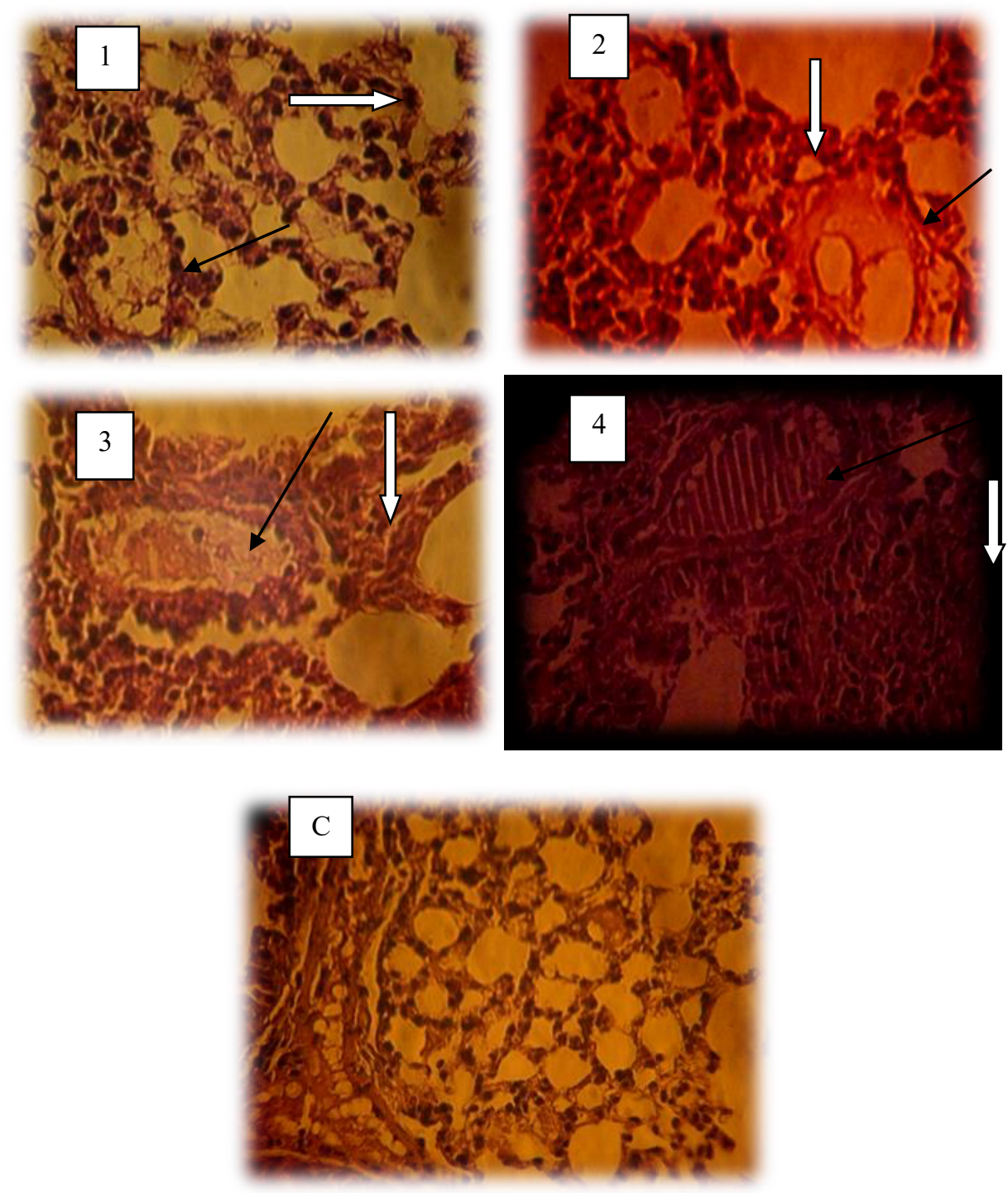

Figure 5: Histopathological sections of mice lung

Sections 1, 2, 3 and 4 lung histopathological sections of mice injected with 100, 200, 300 and $400 \mathrm{pg}$ respectively, $\mathrm{C}$ is controlnegative lung tissue. There is a thickening in alveolar walls (white arrows in all sections). Mucin accumulation in the alveoli is in sections 1, 2, and 3 (black arrows); blood vessels congestion is in section 4 (black arrow). The lesions are increased with increasing of the injected exotoxin A. 

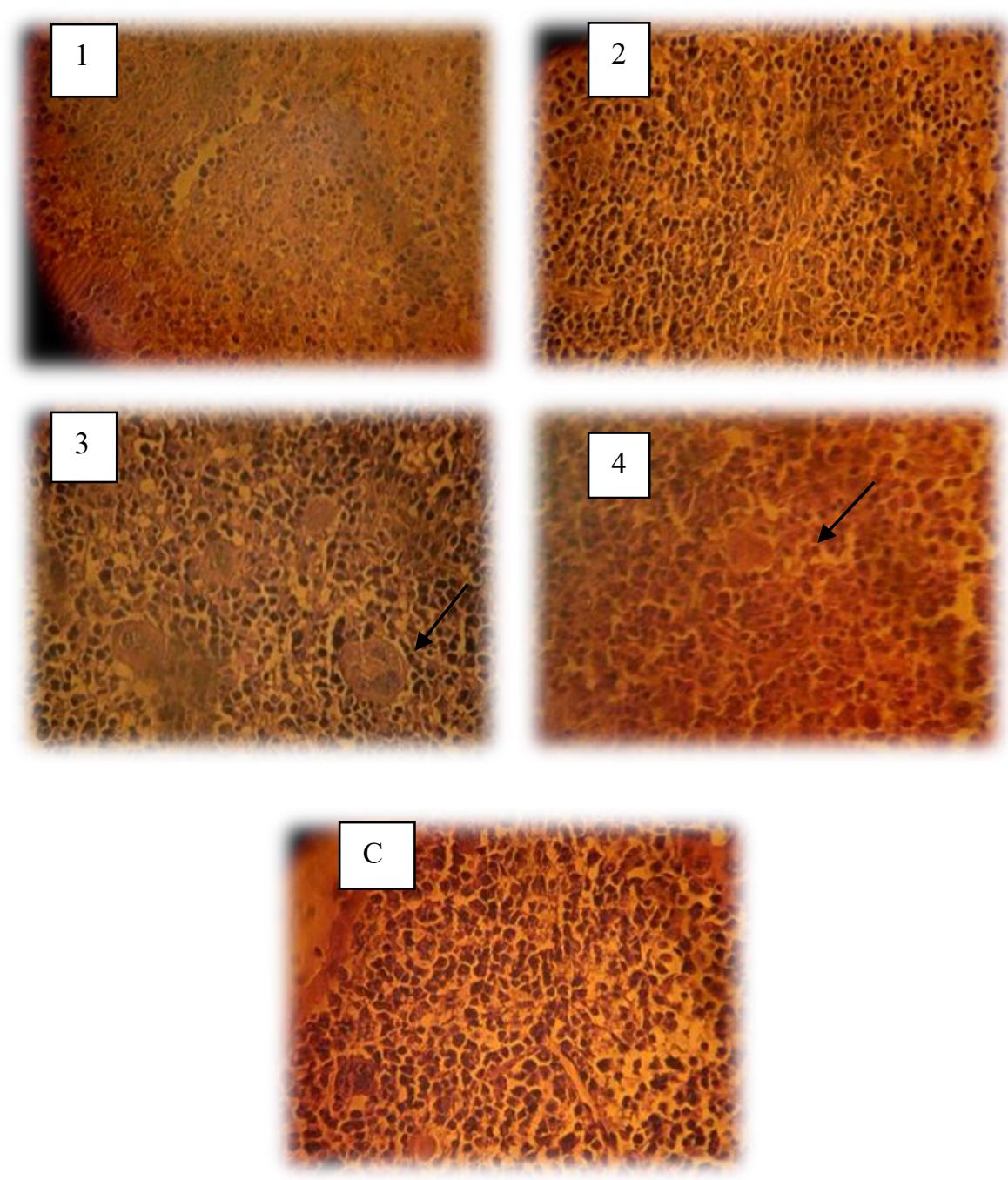

Figure 6: Histopathological sections of mice spleen

Sections 1, 2, 3 and 4 spleen histopathological sections of mice injected with 100, 200, 300 and $400 \mathrm{pg}$ respectively. $\mathrm{C}$ is controlnegative spleen. Enlargement of white pulp appeared in sections 3 and 4 (arrows). 

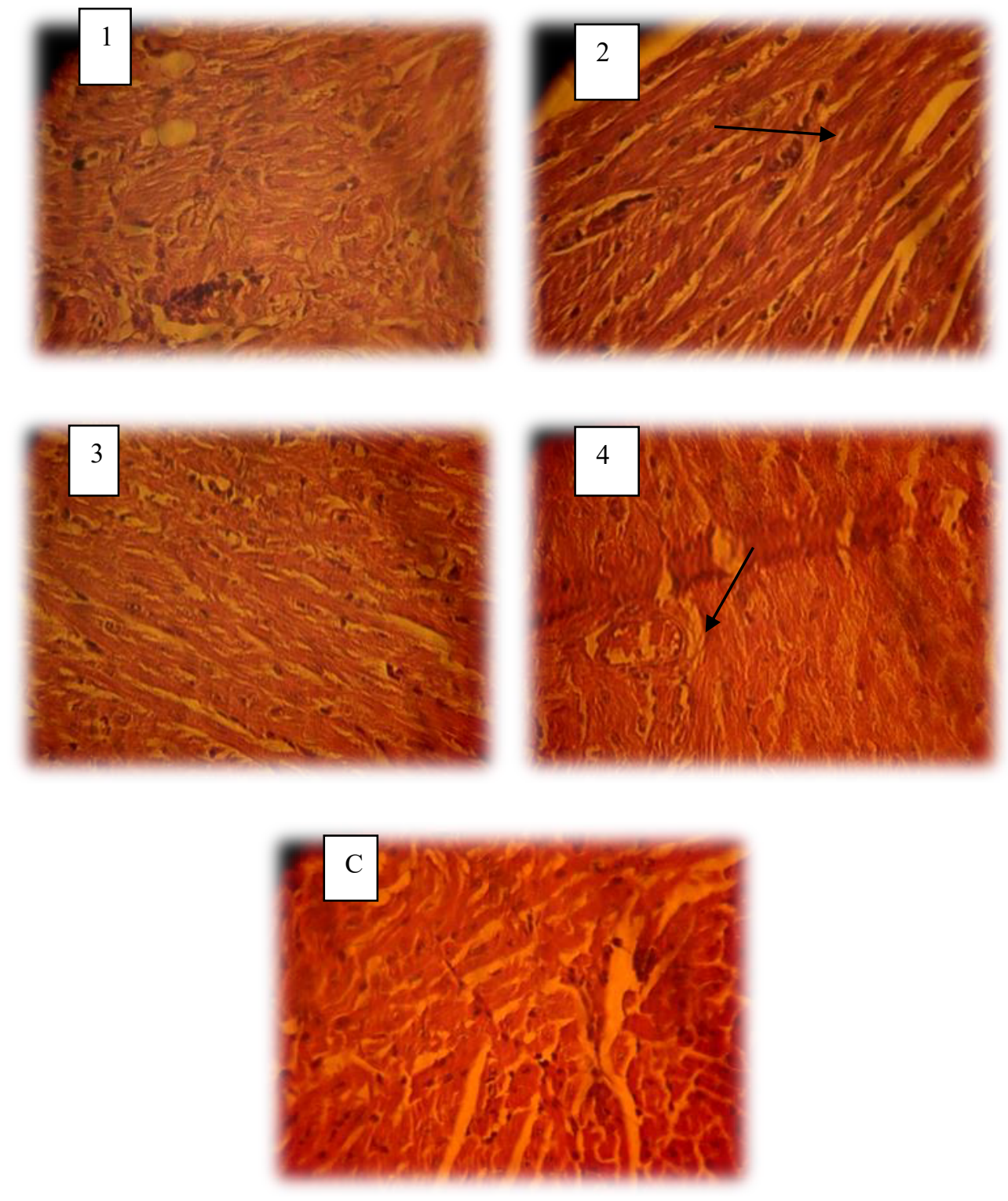

Figure 7: Histopathological sections of mice heart

Sections 1, 2, 3 and 4 heart histopathological sections of mice injected with 100, 200, 300 and $400 \mathrm{pg}$ respectively. $\mathrm{C}$ is controlnegative heart. Blood vessel congestion in section 4 (arrow) and degenerative changes are in section 2 (arrow).

\section{Discussion}

Pseudomonas aeruginosa is still in the front of otitis media pathogens especially in chronic infection cases in all ages of the current study and it is not far from the results obtained by other studies $(16,17,18)$. The pathogenicity and severity of $P$. aeruginosa infection arerelated to excreting its own toxins and other harmful products (19). The most powerful exotoxinof $P$. aeruginosais exotoxin $\mathrm{A}(20,21)$.A high percentage of clinical $P$. aeruginosaisolates carry tox $A$ gene on their chromosome the percentage may reach to $100 \%$ (3)as reported here. 
Previously some observations were reported as $P$. aeruginosa can grow and multiplies in unsympathetic conditions like disinfectants $(22,23)$ but whether or not it is able to produce its extracellular toxin in such condition is still mysterious. The mainaspect in $P$. aeruginosa distinction as a pathogen is its intrinsic resistance to antibioticsand disinfectants.Furthermore, the complete genome sequence of $P$. aeruginosa highlights the adaptability and intrinsic antibiotics and disinfectants resistance of $P$. aeruginosa (22). The simple salts-based media of this study has proved to not only encourage $P$. aeruginosa to grow but also to induce exotoxin A production.Pseudomonas aeruginosa isolates were varied in exotoxin A production, this may be due to individual variation in gene expression (24). Despite the simplicity of the medium by which the exotoxin A was produced, $P$. aeruginosa isolates still produce relatively good amounts of exotoxin A. This presumably explain the virulence of $P$. aeruginosa even in poor nutrition environment.Even in presence of trace amount of iron, that well known asan inhibitor of exotoxin A production, and omitting of glutamate that enhances the exotoxin A production(25), $P$. aeruginosa isolates still produce exotoxin A. Moreover, exotoxin A at these low concentrations can induce histopathological lesions in the mice vital organs and these effects increase with the increasing of exotoxin A concentration.From this point of view, $P$. aeruginosa isolates are able to produce exotoxin Aat amounts that can exert its harmful effect on vital organ tissues.Hence exotoxin A affect internal vital organs at low concentration reached 100picograms as proved by this studyto few micrograms as reported previously $(26,27)$.

As a conclusion,Pseudomonas aeruginosa is still in the front of otitis media pathogens and toxA gene is predominant on their chromosomes. Even in poor nutrition conditions and the presence of trace amounts of iron, $P$. aeruginosa isolates are still able to grow and produce exotoxin A at amounts can exert its harmful effect on mice vital organs.

Acknowledgment: The author would like to thank Biology Department/College of Science/Mustansiriyah University (www uomustansiriyah.edu.iq) for its support the present work.

\section{Conflicts of interest}

There are no conflicts of interest.

\section{References}

1- VergisonA, DaganR, ArguedasA, Bonhoeffer J, CohenR, DHooge I, RayGT. Otitis media and its consequences: beyond the earache. Lancet infects.Dis.2010; 10(3):195-203.

2- Oyeleke SB. Screening for bacterial agents responsible for otitis media and their antibiogram. African J. Microbiol. Res.2009; 3(5): 249-252 .

3- Auda IG, AL_Kadmy IMS, Ali, ANM. Muslim SN, Salman IMA. toxA gene as a chromosomal marker for rapid identification of otitis media Pseudomonas aeruginosa. Int. J. Adv. Chem. Engg. Biol. Sci. 2015;2 (10): 40-42.

4- Wideman WL.Pseudomonas aeruginosa otitis media and interna in a chinchilla ranch. Can. Vet. J. 2006; 47(8): 799-800.

5- Hobson CE, MoyJD, ByersKE, RazY, Hirsch BE, McCall AA. Malignant otitis externa: evolving pathogens and implications for diagnosis and treatment. Otolaryngol. 2014; 151(1): 112-116.

6- Todar. K.Todar s Textbook of bacteriology. $1^{\text {sted. }}$ Madison and Wisconsin. 2008.

7- Du X, Youle RJ, FitzGerald DJ,Pastan I. Pseudomonas exotoxin A-mediated apoptosis is Bak dependent and preceded by the degradation of Mcl-1. Mol. Cell. Biol. 2010; 30(14): 3444-3452.

8- Ochsner UA, Johnson Z, Lamont IL, Cunliffe HE, Vasil ML. Exotoxin A production in Pseudomonas aeruginosa requires the iron-regulated pvdS gene encoding an alternative sigma factor.Mol. Microbiol. 1996;21(5):1019-28.

9- Forbes BA, Sahm DF, WeissfeldAS. Diagnostic Microbiology.10th ed. Mosby. USA. 2002.

10- Lianes C, HocquetD,VogneC, Benali-Baitich D, NeuwirthC, Plésiat,P.Clinical strains of Pseudomonas aeruginosa overproducing MexAB-OprM and MexXY efflux pumps simultaneously. Antimicrob. Agents Chemother. 2004; 48(5): 1797-1802.

11- XavierDE, Picão RC, Girardello R, FehlbergL, Gales AC. Efflux pumps expression and its association with porin downregulation and $\beta$-lactamase production among Pseudomonas aeruginosa causing bloodstream infections in Brazil. BMC Microbiol. 2010; 10: 217-222.

12- Palka-SantiniM, ClevenBE, EichingerL, KrönkeM, KrutO. Large-scale multiplex PCR improves pathogen detection by DNA microarrays. BMC Microbiol. 2009; 9:2180-9. 
13- Sambrook J, Russell D. Molecular Cloning: Laboratory Manual. $3^{\text {rd }}$ ed. Cold Spring Harbor, New York. USA. 2001.

14- Debell RM. Production of Exotoxin A by Pseudomonas aeruginosa in a

Chemically Defined Medium. Infect. Immun., 1979; 24(1): 132-138.

15- Stevens, A. the hematoxylins in: Theory and Practice of Histological Techniques, 2nd edition. Bancrof, J.D. and Stevens,A. London, Churchill livingstone. 1982.

16- Hall-StoodleyL, Hu FZ, Gieseke A, Nistico L, Nguyen D, HayesJ, Wackym PA. Direct detection of bacterial biofilms on the middle-ear mucosa of children with chronic otitis media. Jama. 2006; 296(2): 202-211.

17- Mansoor T, Musani MA, Khalid G, Kamal M. Pseudomonas aeruginosa in chronic suppurative otitis media: Sensitivity spectrum against various antibiotics in Karachi. J. Ayub. Med. Coll. Abbottabad.2009; 21(2): 120-3.

18- Malkappa SK, KondapaneniS, SurpamRB, Chakraverti TK. Study of aerobic bacterial isolates and their antibiotic susceptibility pattern in chronic suppurative otitis media. Indian J. Otol. 2012; 18(3): 136.

19- Bomberger JM, MacEachran DP, CoutermarshBA, Ye S, O'Toole GA, Stanton BA. Long-distance delivery of bacterial virulence factors by Pseudomonas aeruginosa outer membrane vesicles. PLoS Pathogens.2009; 5(4):e1000382.

20- Yates SP, Taylor PL, Jørgensen R, FerrarisD, Zhang J, Andersen GR, Merrill AR. Structure-function analysis of watersoluble inhibitors of the catalytic domain of exotoxin A from Pseudomonas aeruginosa. Biochem. J. 2005; 385(3): 667675.

21- Yates SP, Jørgensen R, Andersen GR, Merrill AR. Stealth and mimicry by deadly bacterial toxins. Trends Biochem. Sci. 2006; 31(2): 123-133.

22- Stover CK, Pham XQ, ErwinAL, Mizoguchi SD, Warrener P, Hickey MJ. Garber RL. Complete genome sequence of Pseudomonas aeruginosa PAO1, an opportunistic pathogen. Nature.2000; 406(6799): 959.

23- Perumal PK, Wand ME, Sutton, JM, Bock, LJ. Evaluation of the effectiveness of hydrogen-peroxide-based disinfectants on biofilms formed by Gram-negative pathogens. J. Hospital Infect.2014; 87(4): 227-233.

24- Gaines JM,Carty NL, Tiburzi F, Davinic M, Visca P. Colmer-Hamood, JA. HamoodAN. Regulation of the Pseudomonas aeruginosa toxA, regA and ptxR genes by the iron-starvation sigma factor PvdS under reduced levels of oxygen. Microbiol. 2007; 153(12): 4219 - 4233.

25- Somerville G, Mikoryak CA, Reitzer L. Physiological characterization of Pseudomonas aeruginosa during exotoxin A synthesis: glutamate, iron limitation, and aconitase activity. J. Bacteriol.1999; 181(4): 1072-1078.

26- Al-Muhammadaw KJ. biochemical and molecular study of exotoxin A from a local isolate of Pseudomonas aeruginosa Ph.D. thesis. College of science. Al-Mustansiriyah University. 2006.

27- Manafi A, Kohanteb J, Mehrabani D, Aziz Japoni A, Amini M, Naghmachi M, ZaghiAH, Khalili N. Active immunization using exotoxin A confers protection against Pseudomonas aeruginosa infection in a mouse burn model. BMC Microbiol. 2009; 9: 23. 